\title{
An intrinsically disordered linker controlling the formation and the stability of the bacterial flagellar hook
}

\author{
Clive S. Barker', Irina V. Meshcheryakova ${ }^{1}$, Alla S. Kostyukova ${ }^{2}$, Peter L. Freddolino ${ }^{3}$ and Fadel A. Samatey ${ }^{1 *}$ (D)
}

\begin{abstract}
Background: In a macro-molecular complex, any minor change may prove detrimental. For a supra-molecular nano-machine like the bacterial flagellum, which consists of several distinct parts with specific characteristics, stability is important. During the rotation of the bacterial flagellar motor, which is located in the membrane, the flagella rotate at speeds between 200 and 2000 rpm, depending on the bacterial species. The hook substructure of the bacterial flagellum acts as a universal joint connecting the motor to the flagellar filament. We investigated the formation of the bacterial flagellar hook and its overall stability between the FlgE subunits that make up the hook and attempted to understand how this stability differs between bacteria.

Results: An intrinsically disordered segment plays an important role for overall hook stability and for its structural cohesion during motor rotation. The length of this linker segment depends on the species of bacteria; for Salmonella enterica and Campylobacter jejuni it is approximately 37 and 54 residues, respectively. Few residues of the linker are conserved and mutating the conserved residues of the linker yields non-flagellated cells. In the case of Campylobacter, which rotates its flagella at a speed much higher than that of Salmonella, shortening the linker leads to a rupture of the hook at its base, decreasing cell motility. Our experiments show that this segment is required for polymerization and stability of the hook, demonstrating a surprising role for a disordered region in one of the most finely tuned and closely studied macromolecular machines.

Conclusions: This study reveals a detailed functional characteristic of an intrinsically disordered segment in the hook protein. This segment evolved to fulfill a specific role in the formation of the hook, and it is at the core of the stability and flexibility of the hook. Its length is important in the case of bacteria with high-speed rotating flagella. Finding a way of disrupting this linker in Campylobacter might help in preventing infections.
\end{abstract}

Keywords: Intrinsically disordered peptide, Supra-molecular complex, Protein stability, Motility, Universal joint, Bacterial flagellum

\section{Background}

A protein's function is linked to its three-dimensional structure [1,2], which is correlated with its amino acid sequence [3]. However, intrinsically disordered polypeptides have little or no well-defined secondary or tertiary structures, and their functions depend on this lack of structure [4]. In the bacterial flagellum, although ordered domains are important for its function [5-7], a

\footnotetext{
* Correspondence: bakary.macy.samatey@gmail.com

${ }^{1}$ Trans-membrane Trafficking Unit, Okinawa Institute of Science and Technology Graduate University, 1919-1 Tancha, Onna, Kunigami, Okinawa 904-0495, Japan

Full list of author information is available at the end of the article
}

disordered region is found to be crucial for its stability. In flagellated bacteria, the axial part of the flagellum can be divided in three sections made by the filament, the hook, and the rod [8] (Fig. 1). The filament functions like a propeller, the hook is a universal joint that transmits the torque to the filament [8], and the rod is directly connected to the motor located in the membrane and works like a drive-shaft, connecting the motor to the hook [9-11]. While in most bacteria the filament and the hook are made by the assembly of multiple copies of FliC and FlgE, respectively [12, 13], the rod is made by the association of many different proteins $[14,15]$. The distal part of the rod is formed by approximately $50 \mathrm{FlgG}$ subunits and is 


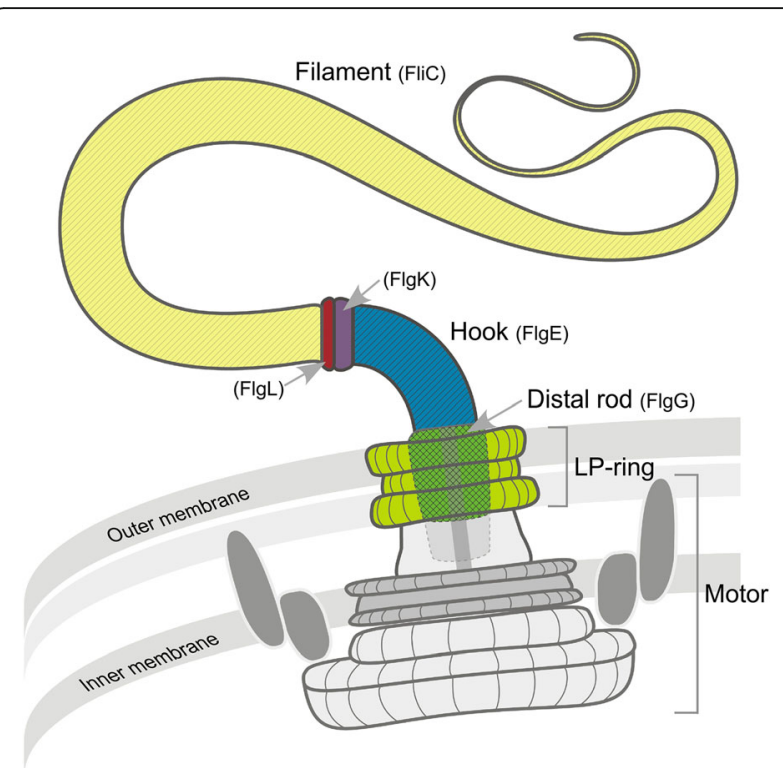

Fig. 1 Schematic representation of the flagellum from a gram-negative bacterium. The distal rod (green), located in the outer membrane, is in direct contact with the hook (blue). Between the hook and the filament (yellow) are two junction proteins - FlgK (purple) and FlgL (red). The rod transmits the torque produced by the motor to the hook. During the rotation, the rod is held in place by the LP-ring

directly in contact with the hook [16]. The structures of FlgE and FlgG proteins showed that two domains, D0 and D1, are structurally conserved [6, 16-19]. In Campylobacter jejuni, these domains are connected by a flexible segment previously named the L-stretch because of its shape [19] (Fig. 2a, b, Additional files 1 and 2). This flexible segment that links domains D0 and D1 could not be resolved in FlgE or FlgG structures from Salmonella enterica serovar Typhimurium due to experimental limitations [6, 16, 17, 20].

Sequence alignments of FlgE and FlgG proteins (Fig. 2c, d) from different bacteria show that the segment linking domains D0 and D1 is conserved in both FlgE and FlgG proteins. Both software prediction of disordered protein segments and molecular modeling calculations indicate that this segment is intrinsically disordered and highly flexible (Fig. 2, Additional file 3: Video S1). Compared to the segment connecting domains D0 and D1 of the bacterial filament protein FliC (Leu31-Asp43), the segment in FlgE does not show any clearly defined native state. For FliC, there is a clearly defined low-energy subpopulation of conformations, corresponding to a well-structured native state, which is absent for FlgE. Three-dimensional structure prediction of this segment in FlgE and FlgG of S. enterica, performed with Swiss-Model [21, 22], suggests that it has a disordered structure similar to that of C. jejuni FlgE (Fig. 2, Additional file 2). This segment is hereafter named ID-Rod-Stretch for 'Intrinsically Disordered Rod Stretch' because it is predominantly found in the rod where it has a conserved length. The ID-Rod-Stretch plays an important role in the formation and stability of the hook. This linker becomes partly structured upon formation of the hook, where it is located in a pocket surrounded by molecules of FlgE (Fig. 3a, b). The ID-Rod-Stretch in the distal rod protein FlgG is similar both in length and structure to that in the hook of $C$. jejuni (Fig. 3c-e), and thus likely shows similar structural behavior. To pinpoint which parts of the ID-Rod-Stretch are important for the assembly and function of the hook, we performed targeted mutagenesis of conserved residues in the disordered segment of FlgE from S. enterica. These experiments revealed that this segment is at the center of the stability or flexibility of the hook.

\section{Results}

Lys32 of Salmonella FlgE is required for hook assembly In FlgE, the length of the ID-Rod-Stretch is species dependent, while it is conserved in FlgG with a length similar to that of the ID-Rod-Stretch of FlgE from C. jejuni with 54 amino acid residues. In FlgE from S. enterica, the ID-Rod-Stretch is 37 residues long and goes from Thr28 to Thr64 (Fig. 2c, Additional file 2). Four residues are fully conserved and two are semi-conserved in the $\mathrm{N}$-terminal region of the ID-Rod-Stretch (Fig. 2c, d). In FlgE of $S$. enterica, the four conserved residues correspond to Thr28, Gly30, Lys32 and Phe38, and the two semiconserved residues correspond to Phe31 and Met41. These six residues were exchanged, individually and all together, with alanine residues in order to examine their importance for the structural integrity and function of the hook. To test the expression of FlgE, a $\Delta f l g E$ null mutant strain was transformed with a plasmid carrying the wild-type $f l g E$ gene. Motility and flagellar biosynthesis of the transformed cells were similar to wild-type (Additional file 4). The $\Delta f l g E$ mutant strain was transformed with the plasmids carrying the $f l g E$ genes mutated at codons encoding conserved and semiconserved residues in the ID-Rod-Stretch and motility of the cells was examined in soft tryptone agar (Fig. 4a). The motility of cells expressing FlgE-K32A was severely decreased compared to cells expressing wild-type FlgE and the other five FlgE proteins with point mutations. The strain, which contained the plasmid encoding FlgE-K32A, expressed and exported excess FlgE, at about twice the amount of wild-type (Fig. 4b, c). The strain containing the plasmid encoding wild-type FlgE produced $12 \pm 3$ flagella per cell (Fig. $4 \mathrm{~d}$ ). Less than $10 \%$ of cells of the strain expressing FlgE-K32A produced flagella, and only one or two flagella per cell were made (Fig. 4e). This suggests that FlgE-K32A protein was mainly being exported un-polymerized. 
a

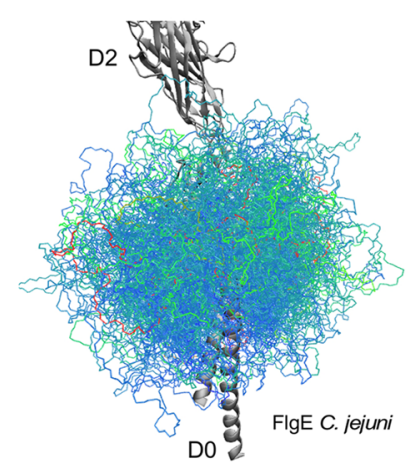

b

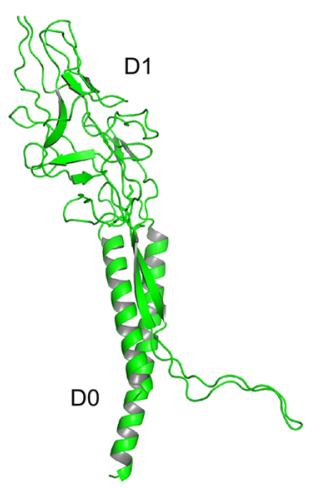

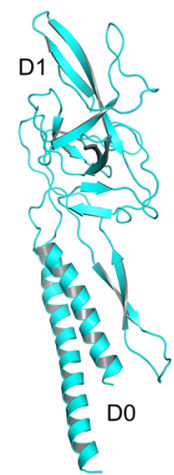

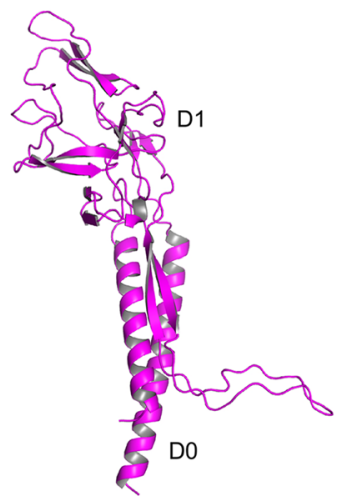

C

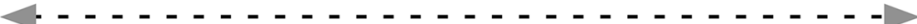

FlgE_Camje 21 EGNNISNVNTTGFKYSRADFGTMFSQTVKIATAPTDGRGGSNPLQIGLGVSVSSTTRIHSQGSVQTTDKNTDV 93 FlgE_Salen 19 IGNNIANSATYGFKSGTASFADMFAGSKV-------------GLGVKVAGITQDFTDGTTTNTGRGLDV 74 FlgE EsCCO 19 IGNNIANSATYGFKSGTASFADMFAGSKV-_-_-_-_-_-_-_--_GLGVKVAGITODFTDGTTTNTGRGLDV 74 FlgE Pseae 19 TGNNIANAGTVGFKOSRAEFADVYAASVLGSGS---------NPQGSGVLLSDVSQMFKQGNIDSTNSVLDL 81 FlgE_Vibch 18 TSNNIANANTFGFKESRAEFGDVYSTSLFTNAK----------TTPGQGVQAAKVAQQFHEGSSIYTNNPLDL 80 FLGE Caucr 23 ISDNIANVNTVGFKRSTSNFSTLVTSGNKNQTY------------SAGGVKAQTHQFISQQGLTQSTTSNLDI 83 FlgE BOrbu 21 VGNNIANVNTIGFKKGRVNFODMISOSISGASRPTDARGGTNPKOVGLGMNVASIDTIHTOGAFOSTOKASDL 93 FlgE_Aquae 21 TSDNLANANTVGFKKSRPIFQDMVSQVVVGL-NTTTGT--VKTTTFGAGAVVDSTQKVWTIGSFKQTEITTDL 90 FlgE Bacsu 21 TSNNIANAQTVGYKKQKAIFDDLLYNNTVGS-RGDGAYAGTNPKSIGNGVKFSGTSTDFSDGSITLTSDKMET 92 FlgE Gilap 19 IGNNIANSATVGFKSASVSFADIYAGSKV-_-_-_-_-_-_-_-_-GMGVKVASVIONFNDGTATTTNNSLDV 74 FlgE_Wiggl 19 IGNNIANSQTVGFKSSAISFSDIFSG-AI---------_-------GLGSQTSGITQNFENGSMLSSAKNLDL 73 FlgE_Sodgm 19 IGNNIANAQTVGFKSSSASFADMFSESMI---------------GLGVQLAGVQQDFNDGTMIAGAGNINM 74

d

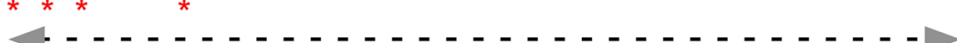

FlgE_Camje 21 EGNNISNVNTTGFKYSRADFGTMFSQTVKIATAPTDG--RGGSNPLQIGLGVSVSSTTRIHSQGSVQTTD-KNTDV 93 FlgG Camje 21 TSNNIANVNTAGFKKSRAEFADLMYOVMKYAGTSTSA-TTLSPSGIEVGVGVRPTAVTKVFTEGNLKSTSTDGLDM 95 FlgG Salen 21 IANNLANVSTNGFKRORAVFEDLLYOTIROPGAOSSE-OTTLPSGLOIGTGVRPVATERLHSOGNLSOTN-NSKDV 94 FlgG_ESCCO 21 IANNLANVSTNGFKRQRAVFEDLLYQTIRQPGAQSSE-QTTLPSGLQIGTGVRPVATERLHSQGNLSQTN-NSKDV 94 FlgG_Pseae 21 ISNNLANVSTTGFKRDRAEFQDLLYQIRRQPGGQSTQ-DSELPSGLQLGTGVRVVGTOKIFTPGSLQTTE-QPLDM 94 FlgG-Vibch 21 ISNNLANASTIGFKKGRAVFEDLFYONINOPGAOSSO-NTRLPSGLMLGAGSKVVATOKVHTNGNVOTTS-NSLDM 94 FlgG_Caucr 20 ISNNIANMNTVGFKRQRAEFQDLLYQTIERAGSQSSSDGNIVPTGVQVGGGVKAGSVYRITEQGTPTLTD-SPLDL 94 FlgG_Borbu 21 IANNLSNVNTTGFKKIRAEFEDLIYQTHNRAGTPATE-NTLRPLGNQVGHGTKIAATQRIFEQGKMQSTN-LLTDV 94 FlgG Aquae 21 ISHNMANVNTVGYKKMRATFODLLYOTVEEPGAPTSP-TTRSPSGFOIGLGTYVSDTYGIFTQGNLTKTD-NQLDI 94 FlgG_Bacsu 21 IGNNIANVNTVGFKKSRVTFKDMVSQTIAGGSAAGAT--IGGTNSKQIGLGSSSGTIDTIHSTSATOSTG-RTLDL 94 FlgG_Gilap 21 ISNNLANVSTGGFKRQRAVFEDLLYQTIRQPGAQSSE-QTTLPSGLQIGTGVRPVATERIHSQGNLELTD-NSNDV 94 FlgG Wiggl 21 ISNNIANVSTNGFKRHRAIFEDLLYOTIROPGSKSSE-OTVLPSGLOIGTGVRPSAALRIHLOGGLTNTG-NETDL 94 FlgG_Sodgm 21 ISNNIANVSTMGFKRQQAVFEDLLYQTVRQPGAKSSE-QTTIPSGLQLGTGVRPVATTRIHLQGGLTNTG-NPTDV 94

Fig. 2 Molecular modeling of the disordered segment and sequence alignment. a Molecular modeling calculations showing the flexibility of the disordered segment of FlgE from C. jejuni. Representative structures, plotted every 10th structure, are sorted and colored by energy for the loop model population (scale ranges from blue (500 Rosetta energy units; REU) to red (850 REU)). b Cartoon representation of the 3D structure of FlgE from C. jejuni, in green, with the "L-shaped" (L-Stretch) disordered segment connecting D0 to D1 obtained, and FlgE and FlgG from S. enterica, in cyan and in purple, respectively. $\mathbf{c}$ and $\mathbf{d}$ Sequence alignments of the rod/hook disordered segment from FlgE and FlgG of gram-negative and -positive bacteria with the position of the disordered segment marked by an arrow. In FlgE (c), the segments have different lengths, while in FlgG (d), the length is conserved. The red stars show the position of the conserved residues. For comparison, the sequence of FlgE from C. jejuni is marked in blue. Camje: C. jejuni, Salen: S. enterica, Escco: Escherichia coli, Pseae: Pseudomonas aeruginosa, Vibch: Vibrio cholerae, Caucr: Caulobacter crescentus, Borbu: Borrelia burgdorferi, Aquae: Aquifex aeolicus, Bacsu: Bacillus subtilis, Gilap: Gilliamella apicola, Wiggl: Wigglesworthia glossinidia, Sodgm; Sodalis glossinidius. Sequence alignment was done with Clustal Omega [30]

The strain expressing FlgE with all four conserved and two semi-conserved residues substituted with alanine residues was non-motile due to the absence of flagella (Fig. 4a, f). However, this FlgE mutant protein was synthesized and secreted at more than twice the amount of wildtype FlgE (Fig. 4b, c). This suggests that the FlgE protein with the substitutions T28A, G30A, F31A, K32A, F38A, and M41A was also being exported un-polymerized, which produced a similar but more severe phenotype to that shown with the K32A substitution alone.
Since the FlgE-K32A mutant had decreased functionality, the $\triangle f l g E$ mutant strain harboring the plasmid carrying the $f l g E(K 32 A)$ mutant gene was incubated in soft tryptone agar for $2-5$ days at $30{ }^{\circ} \mathrm{C}$. Three suppressor mutant strains with increased motility were isolated and the colonies were purified. The plasmids, which were extracted and sequenced, showed that the most motile suppressor mutant strain bore an additional mutation in the ID-Rod-Stretch region of the flgE gene; it encoded a double-mutant protein FlgE-K32A-D62Y. The motility 


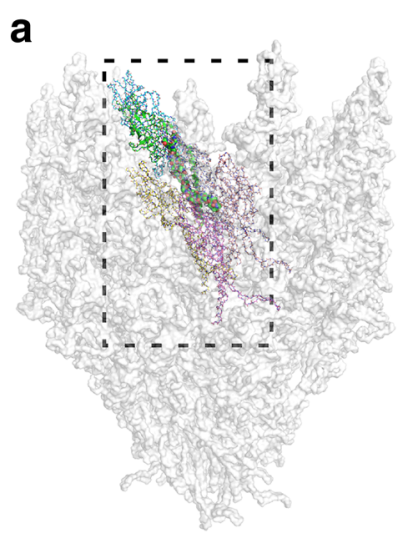

C
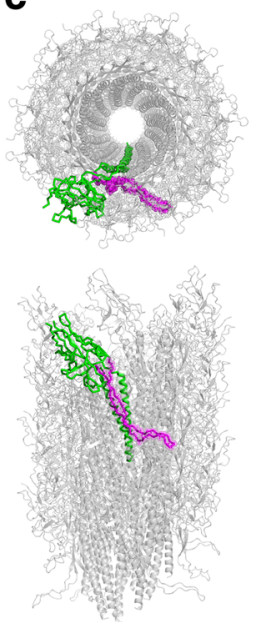

b
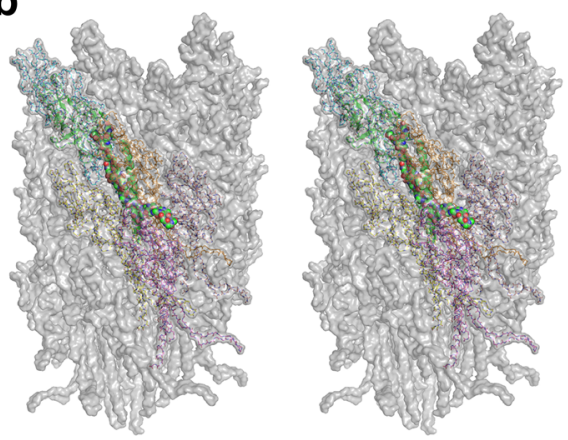

d

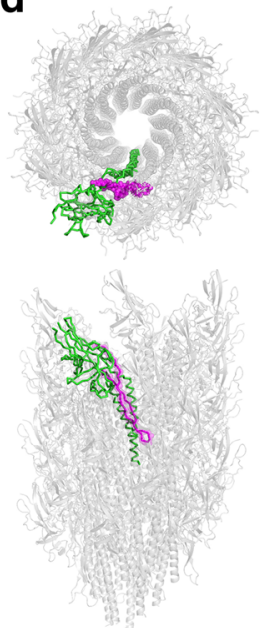

e

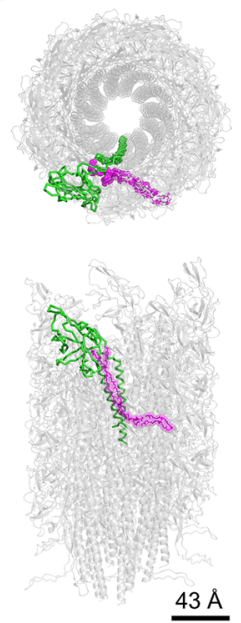

Fig. 3 View of the disordered segment in the hook and in the rod. a Overview of the hook from C. jejuni in grey with six highlighted molecules of FlgE. $\mathbf{b}$ Zoom-up, stereo view of the core domain of the hook with the disordered segment, represented with spheres, surrounded by molecules of FlgE which it interacts with. Comparative view of domains D0 and D1 of the hook of C. jejuni (c), namely the hook and the distal rod of S. enterica in (d) and (e), respectively. The molecules that make the hook and the rod are colored in grey with one molecule colored in green and its disordered segment colored in purple. The upper panels in (c), (d) and (e) show a projection from the distal end. In each case, one molecule is colored in green with the ID-Rod-Stretch represented in magenta. Figure prepared with PyMOL (The PyMOL Molecular Graphic System, Schrödinger, LLC. https://www.schrodinger.com/suites/pymol)

and flagellar biosynthesis of the $\triangle f l g E$ mutant strain freshly transformed with plasmids carrying flgE genes encoding wild-type FlgE, FlgE-K32A, and FlgE-K32AD62Y was examined (Fig. 5). As expected, motility and export of FliC (flagellin protein) was dramatically reduced in cells expressing FlgE-K32A mutant protein (Fig. $4 \mathrm{a}-\mathrm{c}$ ). With the hook not being made, the feedback loop with the $f l i K$ gene [23], which informs the cells about the hook completion, keeps sending a signal that the hook has not been completed. The cells, therefore, do not undergo the secretion-specificity switch that normally occurs upon hook completion [23]. Expression of FlgE-K32A-D62Y increased motility and FliC export compared to the FlgE-K32A mutant protein (Fig. 5a, c). However, cells producing the FlgE-K32A-D62Y doublemutant protein made very few flagella, suggesting that it was still mainly being exported un-polymerized (Fig. 5).
The obtained data demonstrate that Lys32 is important for assembly of the flagellar hook of S. enterica.

\section{The ID-Rod-Stretch is required for hook assembly and mobility}

To study the role of the ID-Rod-Stretch in the assembly and function of the hook, we divided it into short segments of five amino acid residues and mutated them by exchanging them with alanine residues. We assumed that it would reveal the regions that are required for hook structural integrity and those that are required for hook mobility. The first five residues mutated were Ala27-Thr28-Tyr29-Gly30-Phe31, the second set of five residues mutated were Lys32-Ser33Gly34-Thr35-Ala36, and so on. In some cases, the residue was already alanine. The results are summarized in Additional file 5. 

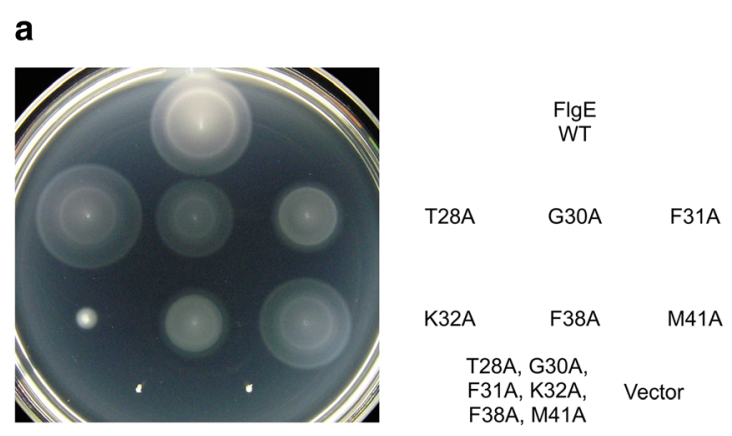

d

e

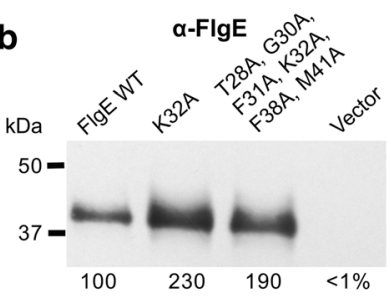

C

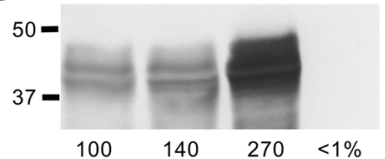

f
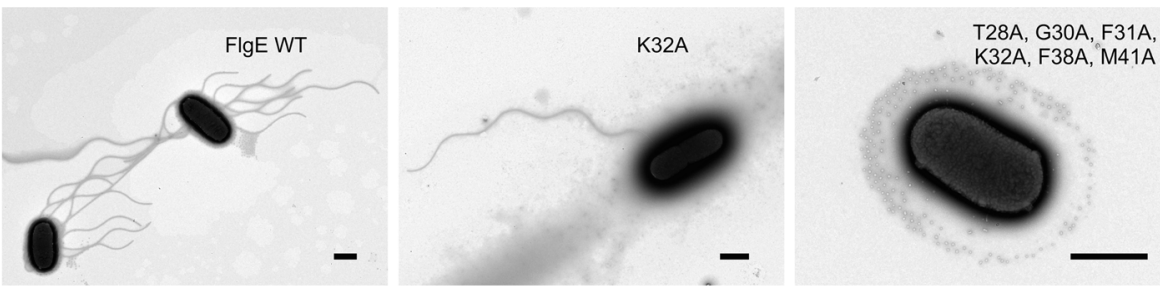

T28A, G30A, F31A,
K32A, F38A, M41A

K32A
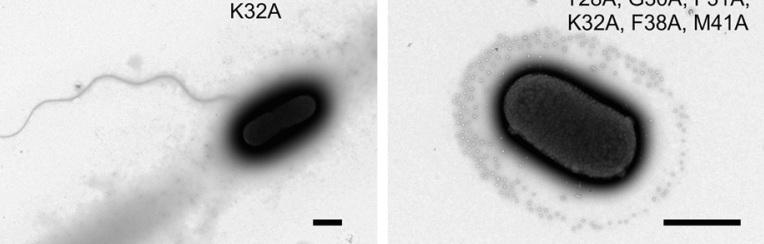

Fig. 4 Motility and flagella of Salmonella expressing FlgE ID-Rod-Stretch mutant proteins. a Motility for strains inoculated into soft tryptone agar that expressed FlgE proteins with conserved amino acid residues exchanged with alanine residues, as indicated. The plate was incubated at $30^{\circ} \mathrm{C}$ for $6 \mathrm{~h}$. Western blot analysis of FlgE proteins exported into the supernatant broth (b) or remaining in the cell pellet fractions after centrifugation (c) for strains grown in $L B$ at $37{ }^{\circ} \mathrm{C}$. Relative band densities (\%) compared to wild-type are indicated. Polyclonal antibodies were used. Wild-type FlgE is $42 \mathrm{kDa}$. Electron micrographs of cells expressing wild-type FlgE (d), FlgE K32A (e), or FlgE T28A, G30A, F31A, K32A, F38A, and M41A mutant proteins $(\mathbf{f})$. Scale bars, $1 \mu \mathrm{m}$

Strains that expressed FlgE AAAAA(27-31) and FlgE AAAAA(32-36) mutant proteins were non-motile, exported excess FlgE, synthesized little FliC, and did not produce flagella (Fig. 6). For the strain that expressed the FlgE AAAAA(32-36) mutant protein, a single flagellum was made by $<5 \%$ of cells. This region is unstructured and at the $\mathrm{N}$-terminus of the ID-Rod-Stretch. The strain that synthesized the FlgE AAAAA(57-61) mutant protein was non-motile, exported excess FlgE, made very little FliC, and did not produce flagella (Fig. 6). This region is unstructured and at the $\mathrm{C}$-terminus of the ID-Rod-Stretch. However, the FlgE AAAAA(62-66) mutant protein was able to function almost as well as wild-type FlgE, which demonstrates that the amino acid composition at the very C-terminal region of the ID-RodStretch is not critical.

The strains that synthesized the FlgE AAAAA(42-46) mutant protein was fully motile and made flagella normally (Fig. 6a, b). These amino acid residues are located in the middle of the ID-Rod-Stretch in the connecting loop region (Additional file 2). Strains that synthesized FlgE AAAAA(37-41), FlgE AAAAA(47-51), and FlgE AAAAA(52-6) mutant proteins were significantly less motile than wild-type and produced decreased amounts of flagella (Fig. 6, Additional file 6). These mutants include the residues that comprise the two ID-Rod-Stretch N- and $\mathrm{C}$-terminal region anti-parallel $\beta$-strands. Examination by dark-field microscopy revealed that some cells within the populations were motile, but were less so than wild-type. The amount of the FlgE AAAAA(37-41) mutant protein in the supernatant broth was approximately $40 \%$ that of wild-type (Fig. 6d) and yet the amount of this protein in the cell pellet was slightly more than in wild-type (Fig. 6c). If cells do not undergo a switch from rod/hook-type export substrates to filament-type export substrates [23], FlgE will continue to be produced, which may account for more FlgE than wild-type.

\section{Campylobacter FlgE has a long ID-Rod-Stretch vital for hook stability}

The ID-Rod-Stretch of FlgE from C. jejuni strain 81116 has an insertion of approximately 20 residues in its middle compared to $S$. enterica LT2 FlgE. This region was shown to be involved in inter-subunit interactions in the hook [19]. To study the importance of this insertion, a strain of $C$. jejuni was made where the $f l g E$ gene was changed by deleting the codons for 21 amino acid residues from Gln46 to Ile66. The deletion was designed based on the structure of C. jejuni FlgE [19].

Motility in Mueller-Hinton motility media at $42{ }^{\circ} \mathrm{C}$ and the flagellar assembly phenotypes of four strains of C. jejuni were examined (Fig. $7 \mathrm{a}-\mathrm{e}$ ). The four strains were the wild-type strain, a $\Delta f l g E\left(\Delta f l g E:: \mathrm{Km}^{\mathrm{R}}\right)$ deletion mutant strain, a $\Delta f l g E+$ FlgE pseudo-wild-type strain, 


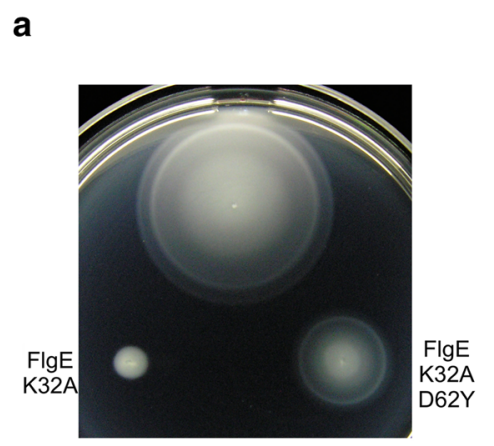

f

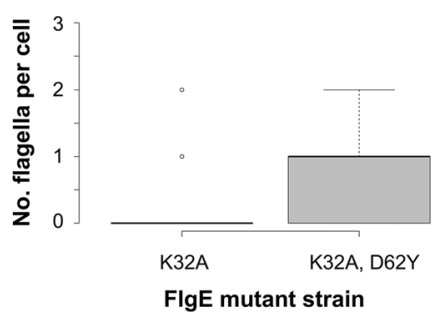

b

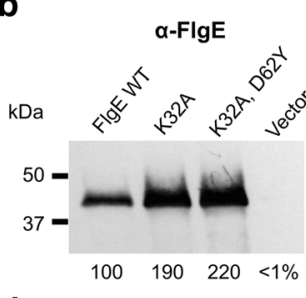

d

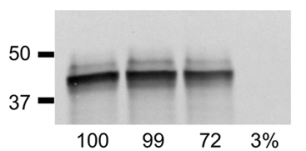

g

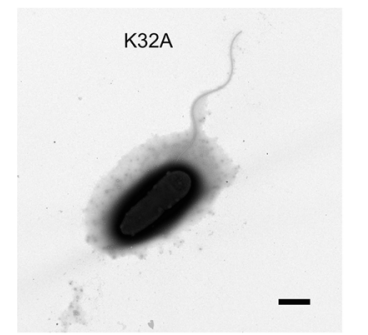

C

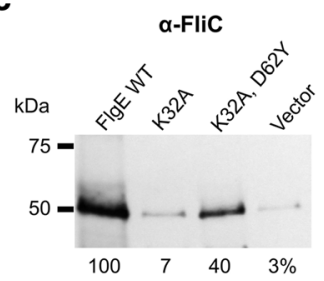

e

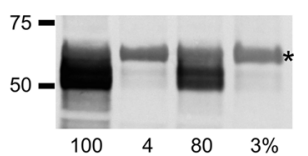

h

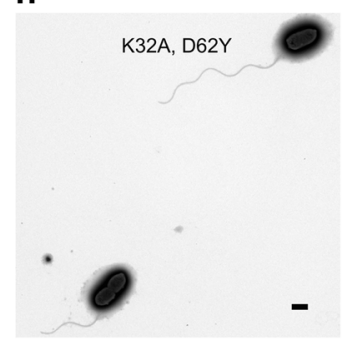

Fig. 5 Lys32 of Salmonella FlgE is important for hook assembly. a Motility in soft tryptone agar of an S. enterica $\Delta$ flgE null mutant strain that harbored plasmids carrying genes encoding the wild-type FlgE protein, a FlgE K32A mutant protein, or a FlgE K32A D62Y double-mutant protein. The plate was incubated for $10 \mathrm{~h}$ at $30{ }^{\circ} \mathrm{C}$. Western blot analysis using polyclonal antibodies towards FlgE (b and $\left.\mathbf{d}\right)$ and FliC (c and e) proteins exported into the culture supernatant broth (b and $\mathbf{c}$ ) or in the cell pellet fractions after centrifugation (d and $\mathbf{e})$. The bacteria were grown in LB to early stationary phase at $37^{\circ} \mathrm{C}$. Relative band densities (\%) compared to FlgE wild-type are indicated. FliC is $51 \mathrm{kDa}$ and wild-type FlgE is $42 \mathrm{kDa}$. An asterisk in (e) indicates a non-specifically bound protein. Box plot (f) displaying the distribution of the numbers of flagella per cell, for $>30$ cells, and

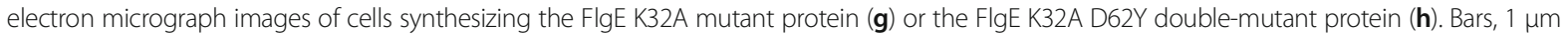

and a $\Delta f l g E+$ FlgE $\Delta(46-66)$ ID-Rod-Stretch mutant strain. The $\triangle f l g E$ deletion mutant strain was non-motile and did not produce flagella. The small amount of flagellin $(8 \%)$ released by the $\Delta f l g E$ mutant strain was presumably due to cell lysis (Fig. 7c). The pseudo-wild-type strain, which bore a $\triangle f l g E$ gene deletion and encoded the wild-type flgE gene integrated into the rRNA gene cluster, was fully motile and assembled flagella normally. The $\Delta f l g E+$ FlgE $\Delta(46-66)$ ID-Rod-Stretch mutant strain was much less motile than the wild-type strain (Fig. 7a), yet it synthesized and exported FlgE and flagellin at similar amounts to the wild-type strain (Fig. 7b-e). However, when negatively stained cells of the $\triangle$ flgE + FlgE $\Delta(46-66)$ ID-Rod-Stretch mutant strain were examined by transmission electron microscopy, many broken flagella were seen on the grid surface compared to the wild-type strain at $2000 \times$ magnification (Fig. $7 f$, g). At $25,000 \times$ magnification, it was revealed that the flagella of the $\Delta f l g E+$ FlgE $\Delta(46-66)$ ID-Rod-Stretch mutant strain were breaking at the hook (Fig. $7 \mathrm{~h}$ ). The surfaces of several electron microscope grids were scanned at low power $(1000 \times)$ magnification for each strain. A surface area covering at least 30 evenly distributed cells was scanned for each grid. The number of cells with one, two, or no flagella and free broken flagella were counted for each grid and the numbers were normalized to 30 cells for each grid. Compared to wild-type strain, there were more than ten times the number of broken flagella with the FlgE $\Delta(46-66)$ ID-Rod-Stretch deletion mutant strain (Fig. 7i).

Based on the micrographs that we have of the wildtype unbroken hook attached to cells and the broken hooks of the ID-Rod-Stretch deletion mutant strain, the wild-type hook of $C$. jejuni has a mean length of $105 \pm 8 \mathrm{~nm}(N=7)$, while the broken hooks have an average length of $85 \pm 15 \mathrm{~nm}(N=23)$. Almost intact hooks were attached to the filament. We did not see any breakage of the hook without filament, which makes us suspect that, in the absence of the filament, the hook will probably not break. The point of breakage is close to the rod-hook junction. During the growth of the flagellum, the hook assembles normally, followed by the completion of the flagellum. In the case of a shortened ID-Rod-Stretch in the hook, interactions between FlgE and FlgG proteins at the rod-hook interface and between FlgE proteins in the hook are reduced. As the filament is being assembled, the load on the hook gradually weakens the rod-hook connection, inducing breakage of the hook. 
a

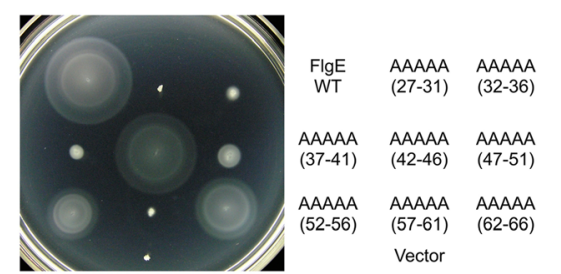

C

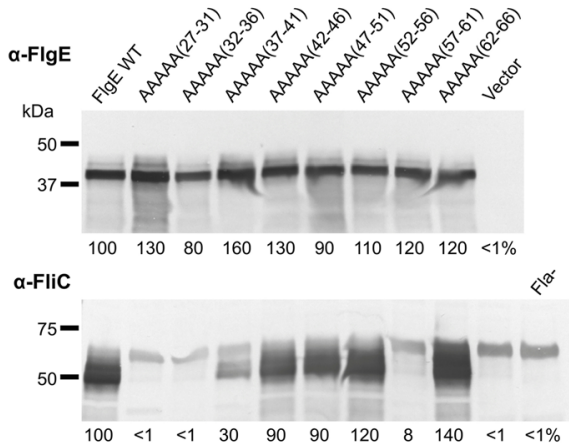

b

d
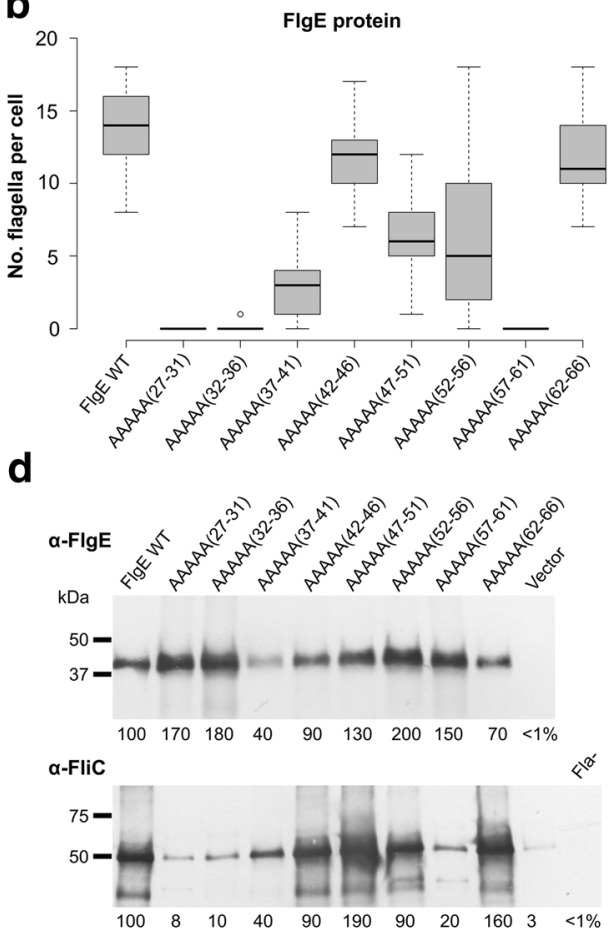

Fig. 6 Motility and biosynthesis of flagella is decreased for Salmonella ID-Rod-Stretch mutant strains. a Motility phenotype in soft tryptone agar of a $\Delta$ flgE null mutant strain that harbored plasmids carrying flgE mutant genes. FlgE proteins were encoded with five amino acid residues exchanged with five alanine residues. The plate was incubated at $30^{\circ} \mathrm{C}$ for $6 \mathrm{~h}$. Box plot (b) displaying the distribution of the numbers of flagella per cell, for $>30$ cells of each strain examined using transmission electron microscopy. Western blotting analysis of the amount of FlgE and FliC in the cell (c) and exported (d) into the culture supernatant broth for cultures of the strains grown in LB to early stationary phase at $37^{\circ} \mathrm{C}$. Polyclonal antibodies were used. The Fla- strain does not produce flagella. Relative band densities (\%) compared to wild-type are indicated. FliC is $51 \mathrm{kDa}$ and wild-type FlgE is $42 \mathrm{kDa}$

\section{Discussion}

Intrinsically disordered peptides often interact with many different proteins [24] and are known for their involvement in important processes in cells [25]. Mutations in the disordered regions induce a reduction in these interactions as well as dysfunction in cells, which often lead to diseases. In the bacterial flagellum, the ID-Rod-Stretch will not only connect two different domains within the protein, but will also interact with several neighboring molecules in both the hook and rod.

Compared to C. jejuni, the ID-Rod-Stretch of FlgE from $S$. enterica undergoes fewer interactions with other molecules of FlgE in the hook because of its shorter amino acid length (Figs. 2 and 8). Among mutations of the conserved residues, the mutations T28A and M41A do not have any effect on the growth of the flagellum and on bacterial motility. The substitution of the conserved Lys32 by an alanine in FlgE from S. enterica drastically decreases flagellar biosynthesis. Based on the structure of FlgE from $C$. jejuni and on the model of the ID-Rod-Stretch of $S$. enterica obtained by homology modeling using Swiss-Model [21, 22], Lys32 in FlgE from S. enterica has contacts with Asp62, in the ID-Rod-Stretch, and with Arg95 and Glu361 both located in domain D1 of the same molecule (Fig. 8a, Additional file 7). Similar contacts are found in the structure of FlgE from C. jejuni [19], with residue Lys34 in close contact with Gln81 and Arg115 and forming a salt bridge with Glu809; these four residues respectively correspond to Lys32, Asp62, Arg95, and Glu361 of FlgE from S. enterica. Residues Lys32, Arg95, and Glu361 are highly conserved in bacterial FlgE proteins. The K32A mutation seems to disrupt the interactive pocket of Lys32 that coordinates the connection between the N-terminal region of the ID-Rod-Stretch with domain D1 (Fig. 8a).

Both mutations F31A and F38A decrease the motility, but less severely than the effect of the mutation K32A. However, the exchange of all four conserved amino acid residues, Thr28, Gly30, Lys32, and Phe38, and the two semi-conserved residues, Phe31 and Met41, of the IDRod-Stretch with alanine residues has a cumulative effect that results in non-flagellated cells of S. enterica. Among these residues, Thr28, Gly30 and Phe31 are close to Lys32. Substitutions to alanine residues at these positions accentuate the effect of the $\mathrm{K} 32 \mathrm{~A}$ substitution, leading to non-flagellated cells. These mutations should 


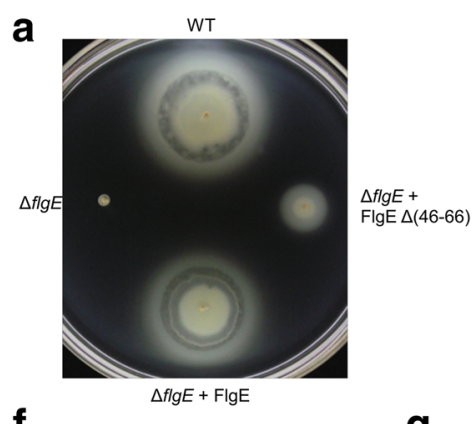

f

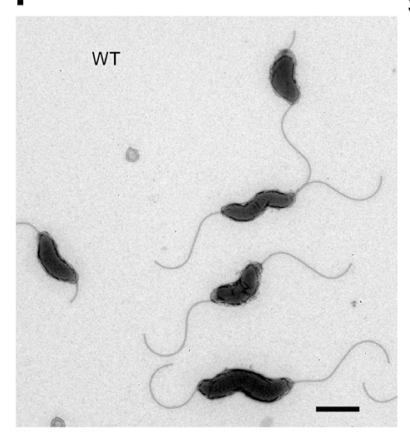

g
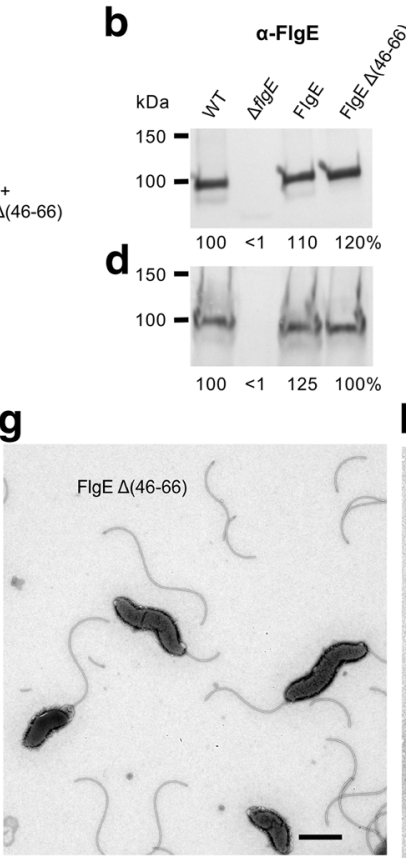

h
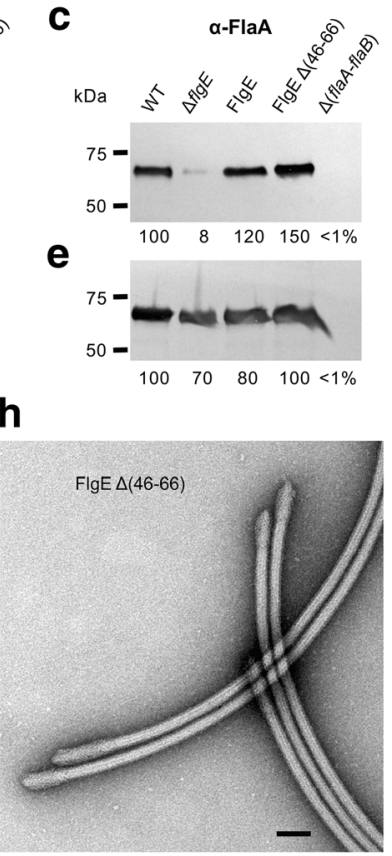

i

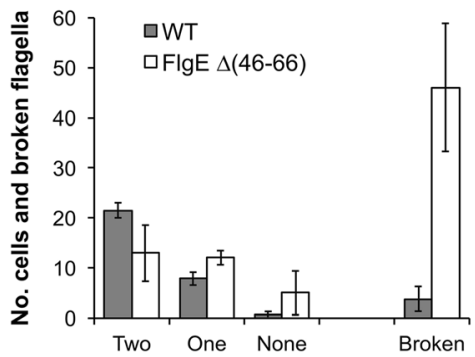

Cells with two, one or no flagella and broken flagella

Fig. 7 Decreased motility and flagellar breakage for a Campylobacter ID-Rod-Stretch deletion mutant strain. a Motility for a wild-type strain, a $\Delta$ flgE mutant strain, a $\Delta$ flgE mutant strain encoding an inserted copy of the wild-type flgE gene, and a $\Delta$ flgE mutant strain encoding a gene for a FlgE mutant protein deleted for amino acid residues $46-66$, inoculated into Mueller-Hinton motility media. The plate was incubated at $42^{\circ} \mathrm{C}$ for $24 \mathrm{~h}$. Western blotting analysis of FlgE (b) and FlaA (flagellin) (c) proteins exported into the culture supernatant, and FlgE (d) and FlaA (e) protein synthesis for whole cells, using polyclonal antibodies. Cultures of the strains were grown in Mueller-Hinton broth at $42^{\circ} \mathrm{C}$ to stationary phase. Relative band densities (\%) compared to wild-type are indicated. Electron micrographs at 2000x magnification of C. jejuni expressing wild-type FlgE (f) and FlgE $\Delta(46-66)(\mathbf{g})$. Scale bars, $1 \mu \mathrm{m}$. $\mathbf{h}$ Electron micrograph at 25,000× magnification of flagella broken at the hook for cells expressing FlgE $\Delta(46-66)$. Scale bar, $50 \mathrm{~nm}$. i Quantification of flagella. Cells with and without flagella and surrounding broken flagella were counted at 1000x magnification for at least 30 cells on three carbon grids for the wild-type and FlgE $\Delta(46-66)$ strains. The numbers were normalized to 30 cells per grid and mean average numbers per grid and standard deviations are shown

have the same effect on all ID-Rod-Stretch with lengths similar to that of $S$. enterica.

The ID-Rod-Stretch can be divided in two classes. The first class, made of short ID-Rod-Stretch, is found only within some FlgE proteins, such as in S. enterica, and is made of approximately 30 amino acid residues (Additional file 2). The second class, with long ID-Rod-Stretch, is found in all FlgG proteins and in a few FlgE proteins, such as in $C$. jejuni, and is made of approximately 60 amino acid residues (Additional file 2). Mutating the conserved residues from the short ID-Rod-Stretch will produce non-flagellated, non-motile cells. However, these mutations will not have the same drastic effect on the long ID-Rod-Stretch due to the extensive set of interactions with other molecules (Fig. 8c). These interactions do not exist in the case of a short ID-Rod-Stretch.

C. jejuni strains encoding FlgE AAAAA(27-31) and FlgE AAAAA(32-36) mutant proteins are non-motile for similar reasons. These amino acid substitutions affect some of the conserved residues and might directly affect the stability of the $\beta$-strands. These regions of the ID-Rod-Stretch are very important for the assembly of the 


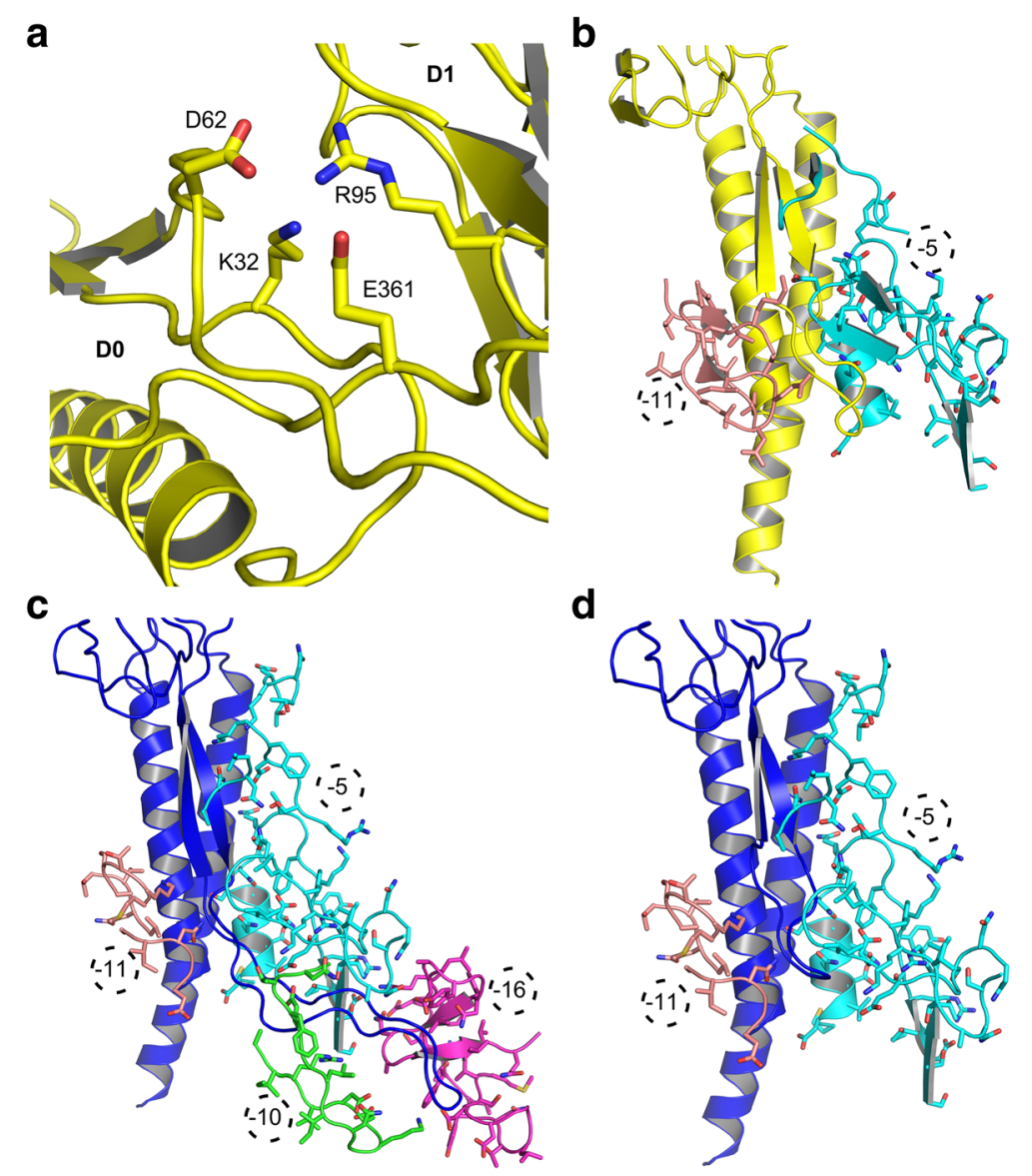

Fig. 8 Analysis of the effect of mutations in the structural context of the hook. Analysis of the different mutations in the ID-Rod-Stretch: (a) Lys32 of S. enterica FlgE, a conserved residue of the ID-Rod-Stretch, is located in a pocket with Asp62, Arg95, and Glu361 in this theoretical model. Both Arg95 and Glu361 are conserved in the FlgE protein family. b Two of the three molecules of FlgE, at position "-5" (cyan) and "-11" (light brown), which interact with the modeled ID-Rod-Stretch of the flagellar hook of S. enterica. Mutations in the ID-Rod-Stretch that are in the interactive domains will affect the stability of the hook. The cryo-electron microscopy structure, including ID-Rod-Stretch of FlgE from C. jejuni [19] (c), is longer than in S. enterica and it is shown here interacting with four FlgE molecules in positions "-5" (cyan), "-10" (green), "-11" (light brown), and "-16" (purple). d Reducing the length of the disordered segment of C. jejuni FlgE reduces its number of interactions with other FlgE molecules in the hook. This has a negative effect on the cohesion of the hook

hook. The strain encoding FlgE AAAAA(42-46) is fully motile because, in $S$. enterica, amino acid residues Phe42 to Lys46 of the ID-Rod-Stretch do not interact with other FlgE molecules. We predict that this will be the same for all bacteria with a ID-Rod-Stretch of similar length to that of $S$. enterica. The strains that produce FlgE with the mutations FlgE AAAAA(37-41), FlgE AAAAA(47-51), and FlgE AAAAA(52-56) are significantly less motile than wild-type because these segments of the ID-Rod-Stretch play important roles in the interaction with other subunits of FlgE in the hook (Fig. 8b).

In the hook of S. enterica, the ID-Rod-Stretch of FlgE interacts with three molecules of FlgE, while in the hook of C. jejuni, the ID-Rod-Stretch of FlgE interacts with five molecules of FlgE (Fig. 8b, c, Additional file 7). In FlgE from $C$. jejuni, the ID-Rod-Stretch is 20 residues longer than that of $S$. enterica. Deletion of these extra residues prevents interactions with two molecules of FlgE from different protofilaments (Fig. 8d). One of these molecules is located in the neighboring protofilament at the "- 16 " position, while the second molecule is located two protofilaments away at the "-10" position (Fig. 8c, d). These interactions cannot be found in the hook of bacteria with a shorter ID-Rod-Stretch, such as S. enterica (Fig. 8b), since their ID-Rod-Stretch does not extend to interact with more FlgE molecules due to a shorter amino acid sequence. Disrupting these sets of interactions reduces the cohesion of the hook of $C$. jejuni. In $C$. jejuni cells expressing FlgE with a shorter ID-RodStretch, flagella, while being assembled normally, detach themselves from the cell by breaking at the site of the hook (Fig. 7). Bacterial flagellar motors rotate at between 100 and $2000 \mathrm{~Hz}$ [26], and the hook undergoes conformational changes while rotating about its axis [27, 28]. The 
interactions between FlgE molecules must ensure the stability of the hook while enabling these conformational changes. The intrinsic disorder of the long C. jejuni ID-Rod-Stretch may be particularly important in this context for enabling adjacent hook monomers to maintain favorable interactions throughout the variety of positions and of conformations encountered during rotation, by providing multiple, nearly isoenergetic conformations that can be accessed as the hook rotates. The flagellar motor of C. jejuni is known to produce a very high torque compared to the flagellar motor of other bacteria [29]. This high torque could be the reason behind FlgE having a long ID-Rod-Stretch. In a recent study, Fujii et al. [16] increased the length of the ID-Rod-Stretch of the hook of $S$. enterica through the insertion of 18 residues taken from the distal rod protein, FlgG, of S. enterica. The authors found that the polyhook assessed became as straight as the rod, concluding that the hook became as rigid as the rod. Our explanation is that the hook became less flexible due to this insertion, but not as rigid as the rod. We have shown that the ID-Rod-Stretch is at the center of stability and flexibility of the hook. However, there is a difference between the reduced flexibility and the rigidity found in the rod. The latter may be, partly, due to the presence of a long ID-Rod-Stretch. In our study, the native hook of $C$. jejuni, with its ID-Rod-Stretch similar to that found in the rod, is fully motile and flexible. If the hook of Campylobacter was as rigid as the rod, it would not have been able to function as a universal joint and the flagellum would not have been able to rotate about its axis. The length of the ID-Rod-Stretch does not change the flexibility of the hook such as to induce a rigid structure similar to that of the rod.

More generally, deleting approximately 20 residues that are inserted in the long ID-Rod-Stretch in both FlgE or FlgG will reduce the interactions between molecules that stabilize the hook or the distal rod, as shown here for the case of C. jejuni (Figs. 7 and 8c, d). This reduction of interactions will destabilize the hook, or the rod, and the flagellum may be ripped off from its base (Fig. 7 h, i).

\section{Conclusion}

The hook disordered segment is important for both the formation and stability of the hook, and thus for cell motility. In the case of pathogenic bacteria, such as $C$. jejuni, which also uses its flagella to secrete toxins, we believe that targeting the ID-Rod-Stretch could be a strategy to prevent toxin secretion into host cells.

\section{Methods}

Protein sequence alignment

Sequence alignment was performed with Clustal Omega [30].

\section{Disorder prediction of the ID-Rod-Stretch}

Prediction of disordered regions was performed using online software Predictor of Natural Disordered Regions (PONDR) [31]. The prediction shows that a part of the segment of C. jejuni FlgE, residues Thr55 to Arg77, has the highest probability of being intrinsically disordered.

\section{ID-Rod-Stretch modeling}

To assess the level of disorder present in the D0-D1 linker of various flagellar components, we generated and analyzed an ensemble of optimized loop structures using the loopmodel module of Rosetta 2016.46.59086 [32]. Fragment libraries were generated for the full-length protein of each target using the Robetta web server [33], and thousands of loop models (2000 for S. enterica FlgE and 3500 for $C$. jejuni FlgE) were subsequently obtained using the quick_ccd modeling method and refine_ccd refinement method. We generated loop models for $S$. enterica FlgE (residues 25-64), C. jejuni FlgE (residues 30-82), and S. enterica FliC (residues 30-44), each in the context of a single full-length protein monomer. Built models were aligned to the corresponding initial structure by the D0 helices (which had been kept rigid during the modeling process), and C $\alpha$ RMSDs calculated between the aligned, modeled loop and the initial structure using the MDAnalysis package [34]. Structural figures and movies were generated using VMD 1.9.3 [35].

\section{Strains and culture conditions}

Bacterial strains and plasmids used in this study are listed in Additional file 8. The following strains and plasmids have been previously described: S. enterica strains SJW1103 [36], JR501 [37], and SJW1368 [38]; C. jejuni strains 81116 [39], CB991 [19], and CB-A9 [19]; and plasmids pKD13 [40], pKD46 [40], pCP20 [41]; pTrc99A-FF4 [42], and pCB956 [19]. S. enterica and E. coli strains were cultured using "Luria-Bertani" broth (LB) or agar at $37^{\circ} \mathrm{C}$ [43]. C. jejuni strains were cultured on Mueller-Hinton agar (Difco, Detroit, MI, USA) and incubated at $42{ }^{\circ} \mathrm{C}$ under microaerophilic conditions $\left(85 \% \mathrm{~N}_{2}, 10 \% \mathrm{CO}_{2}\right.$, and $5 \% \mathrm{O}_{2}$ ) in a Tri-Gas incubator. For E. coli, ampicillin $\left(50 \mu \mathrm{g} \mathrm{mL} \mathrm{m}^{-1}\right)$ was added to media where appropriate. For Salmonella, kanamycin $\left(50 \mu \mathrm{g} \mathrm{mL} \mathrm{m}^{-1}\right)$ and ampicillin $\left(100 \mu \mathrm{g} \mathrm{mL}{ }^{-1}\right)$ were added to media as required. For Campylobacter, trimethoprim $\left(5 \mu \mathrm{g} \mathrm{mL} L^{-1}\right)$, vancomycin $\left(10 \mu \mathrm{g} \mathrm{mL} \mathrm{m}^{-1}\right)$, kanamycin $\left(50 \mu \mathrm{g} \mathrm{mL} \mathrm{m}^{-1}\right)$, and apramycin $\left(60 \mu \mathrm{g} \mathrm{mL}^{-1}\right)$ antibiotics were used where appropriate.

\section{Plasmids}

Oligonucleotides used in the plasmid constructions are listed in Additional file 9. The Salmonella flgE expression plasmid pCB954 was made as follows: the flgE gene was amplified in a PCR reaction with primers Fd-NdeIflgESe and Rv-BamHI-flgESe and strain SJW1103 
genomic DNA template. The PCR product and plasmid pTrc99A-FF4 were digested with Nde I and BamH I restriction enzymes. The digested PCR product and plasmid DNA were ligated using T4 DNA ligase. Other plasmids were derived using site-directed mutagenesis with QuikChange Lightning site-directed mutagenesis kits (Agilent, USA). Standard molecular biology procedures were followed [43].

\section{Construction of Salmonella mutant strains}

To make a $\Delta f l g E::$ FRT null mutant strain the Lambda Red homologous recombination method of Datsenko and Wanner [40] was used. Briefly, an FLP-flanked kananamycin-resistance cassette with ends homologous to $f l g E$ gene was amplified in a PCR reaction with primers Fd-flgESe-FKF and Rv-flgESe-FKF and plasmid pKD13 as template.

\section{Construction of Campylobacter mutant strains}

To make the C. jejuni FlgE ID-Rod-Stretch deletionmutant strain CB-A137, the parent strain CB991, bearing a $\Delta f l g E:: \mathrm{Km}^{\mathrm{R}}$ allele, was transformed naturally with pCB-A128 suicide vector DNA, as previously described $[19,44]$. PCR was used to confirm that doublecrossover homologous recombination had occurred within the rRNA cluster. PCR products were sequenced by chain-termination dideoxynucleotide sequencing using a BigDye Terminator v3.1 cycle sequencing kit (Thermo Fisher Scientific, USA). Strain CB-A137 encodes a flgE IDRod-Stretch deletion mutant gene within the rRNA gene cluster. The rRNA gene cluster has been previously determined to be an appropriate location for insertion of genes for stable gene expression in C. jejuni $[45,46]$.

\section{Motility assays}

Motility of Salmonella strains were examined using soft tryptone agar plates consisting of $0.35 \% \mathrm{w} / \mathrm{v}$ agar containing the appropriate antibiotics [47]. Plates were stabinoculated with colonies of a fresh transformation and incubated at $30{ }^{\circ} \mathrm{C}$ for the desired time. Experiments were repeated at least four times for each strain. For the isolation of suppressor mutant strains with increased motility, colonies were streaked through the soft tryptone agar plate and incubated at $30{ }^{\circ} \mathrm{C}$ for up to 5 days. The suppressor mutant strains were purified by inoculation onto fresh media.

Motility of Campylobacter was examined in MuellerHinton motility media, which contained $0.4 \% \mathrm{w} / \mathrm{v}$ agar [48]. The strains were grown in Mueller-Hinton broth at $42{ }^{\circ} \mathrm{C}$ for $24 \mathrm{~h}$, the optical density of each culture was normalized to $\mathrm{OD}_{600} \mathrm{~nm} 0.5$ and $1 \mu \mathrm{L}$ was stabinoculated into Mueller-Hinton motility media. Motility phenotypes were examined after incubation of strains at $42{ }^{\circ} \mathrm{C}$ for the desired time.

\section{Flagellar protein immunoblotting}

Immunoblotting of exported flagellar proteins and proteins remaining in the cell pellet was performed similarly as described previously $[49,50]$. For Salmonella, cultures were grown in LB at $37{ }^{\circ} \mathrm{C}$ until early stationary phase $\left(\mathrm{OD}_{600} \mathrm{~nm}\right.$ 1.5). Culture broth $(1.5 \mathrm{~mL})$ was sampled and centrifuged at $10,000 \times g$ for $10 \mathrm{~min}$. Cell pellets were frozen, and $1.4 \mathrm{~mL}$ of supernatant broth was put into a clean tube and centrifuged at $20,400 \times g$ for 30 min. Clarified supernatant broth $(1.3 \mathrm{~mL})$ was taken and $150 \mu \mathrm{L}$ of trichloroacetic acid solution was added to precipitate proteins. Supernatant solution samples were centrifuged at $16,100 \times g$ for $30 \mathrm{~min}$ in order to obtain protein pellets. The protein pellets from the supernatant solutions and thawed cell pellets were suspended in Tris.Cl-SDS buffer or $2 \times$ SDS loading buffer $(7 \mathrm{M}$ Urea, $0.1 \mathrm{M}$ Tris. Cl (pH 6.8), $140 \mathrm{mM}$ sodium dodecyl sulfate, $5 \% \mathrm{v} / \mathrm{v} \beta$-mercaptoethanol, $0.2 \% \mathrm{w} / \mathrm{v}$ bromophenol blue) to an equivalent of $27 \mu \mathrm{L} \mathrm{mL}^{-1}$, at $\mathrm{OD}_{600 \mathrm{~nm}} 1.5$ (i.e. the cell pellets were suspended in $40 \mu \mathrm{L} 2 \times$ SDS loading buffer).

For Campylobacter, strains were grown in MuellerHinton broth containing antibiotics as required and grown at $42{ }^{\circ} \mathrm{C}$ under microaerophilic conditions for $24 \mathrm{~h}$. The optical density varied from culture to culture between $\mathrm{OD}_{600} \mathrm{~nm} 0.4$ and 1.2. Cells and proteins from the supernatant broth were harvested by centrifugation of $1.5 \mathrm{~mL}$ culture broth, as described above for Salmonella cultures. The proteins from the supernatant solutions and cell pellets were suspended in Tris.Cl-SDS buffer or $2 \times$ SDS loading buffer to an equivalent of $80 \mu \mathrm{L} \mathrm{mL} L^{-1}$, at $\mathrm{OD}_{600 \mathrm{~nm}} 1.0$.

Samples were loaded onto the wells of a $4-20 \% \mathrm{w} / \mathrm{v}$ Mini-PROTEAN TGX polyacrylamide gel (Bio-Rad, USA) and subjected to electrophoresis at $120 \mathrm{~V}$ for approximately $1 \mathrm{~h}$. Western Breeze chromogenic detection kits were used to detect proteins following manufacturer's instructions (Thermo Fisher Scientific, USA). Band densities were quantified using a ChemiDoc XRS+ gel documentation system with Image Lab Software (Bio-Rad, USA). The following amounts of sample were loaded per well to detect the proteins (the dilutions of sera containing polyclonal antibodies are indicated in parenthesis): Salmonella FlgE, $10 \mu \mathrm{L}$ supernatant protein or $0.5 \mu \mathrm{L}$ cell pellet samples (S. enterica FlgE antibodies, 1:10,000 dilution); Salmonella FliC, $5 \mu \mathrm{L}$ supernatant protein or $0.5 \mu \mathrm{L}$ cell pellet samples (S. enterica FliC antibodies, 1:20,000 dilution); Campylobacter FlgE, $10 \mu \mathrm{L}$ supernatant protein or $10 \mu \mathrm{L}$ cell pellet samples (C. jejuni FlgE antibodies, 1:10,000 dilution); and Campylobacter flagellin, $2 \mu \mathrm{L}$ supernatant protein or $2 \mu \mathrm{L}$ cell pellet samples $(C$. jejuni FlaA antibodies, 1:5000 dilution). Sera from rabbits containing polyclonal antibodies reactive towards $S$. enterica FlgE or FliC were generously provided by $\mathrm{T}$. Minamino (Osaka University). Sera from rabbits containing polyclonal 
antibodies reactive towards C. jejuni FlgE and FlaA proteins were made in this study.

\section{Electron microscopy}

Salmonella strains were examined by electron microscopy similarly as described previously [51]. Cultures were grown in LB with antibiotics as required to late exponential phase $\left(\mathrm{OD}_{600} \mathrm{~nm} \mathrm{1.0}\right)$ at $37{ }^{\circ} \mathrm{C}$. Cell suspensions were spotted on Mextaform HF-34 200-mesh carbon-coated copper grids and the cells were stained with $1 \%$ phosphotungstic acid at $\mathrm{pH} 7$. Grids were examined using a JEM-1230R transmission electron microscope (JEOL, Ltd., Japan) at $100 \mathrm{kV}$. At least 30 negatively stained cells were examined for each strain. Flagella numbers per cell for each strain were compared using a Mann-Whitney $U$ test. Box plots were prepared using BoxPlotR (http://shiny.chemgrid.org/boxplotr/).

Campylobacter strains were examined by electron microscopy similarly as described by Hendrixson and DiRita [48]. Briefly, the strains were grown on MuellerHinton agar, containing appropriate antibiotics, at $42{ }^{\circ} \mathrm{C}$ under microaerophilic conditions for $36 \mathrm{~h}$. Cells were gently scraped from the surface of the plate using a sterile plastic inoculating loop and stained with phosphotungstic acid as described above for Salmonella.

\section{Additional files}

Additional file 1: Molecular modeling calculations on the flagellar rod/ hook intrinsically disordered segment. (A) Plot of energy vs. RMSD to the reference structure for the ID-Rod-Stretch of FlgE of C. jejuni (3500 structures), FlgE of S. enterica (2000 structures), and FliC of S. enterica (1000 structures). Models (A) are generated by Rosetta, blue and red lines show the median energy \pm twice the median absolute deviation. Only low energy structures are shown in the main plot; an inset with the same units shows the distribution for all models, with those in the main plot highlighted in green. Energies are given in Rosetta energy units (REU). Structure distributions showing the flexibility of the ID-Rod-Stretch, in the case of FlgE from $S$. enterica (B) and FliC from S. enterica (C). Structures shown are a random sample of the Rosetta models colored according to their ranking from blue (low energy) to red (high energy). Ranges for the colour scales are 100 to 500 REU (B) or -60 to 40 REU (C). (D) Histograms showing the distribution of energies from the full set of Rosetta models for all three structures under consideration. The disordered nature of the ID-Rod-Stretch sequences is apparent from the lack of any well-separated population of low energy structures, in contrast with similar results from S. enterica FliC; the absence of any favored structure is particularly the case for the large C. jejuni ID-Rod-Stretch. (JPG 3805 kb)

Additional file 2: Comparison of the flagellar rod intrinsically disordered segment in Campylobacter and in Salmonella. (A) View of the linker connecting domains D0 and D1 of the hook protein FlgE in C. jejuni. The linker is colored in cyan. (B) Rainbow colored (from blue to red) view of the ID-Rod-Stretch connecting domains D0 and D1 in FlgE of $C$. jejuni (left, cryo-electron microscopy structure) and S. enterica (right, theoretical model). (C) Sequence alignment of the N-terminal region of FlgE from S. enterica and of C. jejuni. The ID-Rod-Stretch is in blue for S. enterica and red for $C$. jejuni. The four conserved residues in FlgE family are highlighted in yellow. The alignment is performed assuming that the $\mathrm{N}$-terminal methionine is cleaved. (JPG $3170 \mathrm{~kb}$ )
Additional file 3: Video S1. Results of the molecular modeling calculations showing the flexibility of the ID-Rod-Stretch of FlgE from C. jejuni. (MOV $895 \mathrm{~kb}$ )

Additional file 4: Normal flagellar biosynthesis for a Salmonella flaE null mutant strain harboring a plasmid carrying the flgE gene. (A) Motility in soft tryptone agar of the wild-type strain (SJW1103), which harbored empty plasmid vector and a $\Delta$ flgE null mutant strain, which harbored a plasmid carrying the wild-type flgE gene. The plate was incubated for $6 \mathrm{~h}$ at $30^{\circ} \mathrm{C}$. Western blot analysis of FlgE (B) and FliC (C) proteins exported into the culture supernatant broth for cells grown to early stationary phase in $L B$ at $37^{\circ} \mathrm{C}$. FliC is $51 \mathrm{kDa}$ and FlgE is $42 \mathrm{kDa}$. Relative band densities (\%) compared to those of wild-type are labelled. Box plot (D) displaying the distribution of the numbers of flagella per cell, for $>30$ cells, and typical electron micrograph images of the wild-type strain (E) or the $\Delta$ flgE mutant strain that harbored a plasmid carrying the flgE gene (F). Bars, 1 Mm. (JPG $4745 \mathrm{~kb}$ )

Additional file 5: Flagellar phenotypes for S. enterica producing FlgE ID-Rod-Stretch mutant proteins. (DOCX $41 \mathrm{~kb}$ )

Additional file 6: Salmonella expressing FlgE ID-Rod-Stretch mutant proteins. Electron micrographs of representative cells synthesizing FlgE proteins: (A) FlgE wild-type, (B) AAAAA(37-41), (C) AAAAA(42-46), (D) AAAAA(47-51), (E) AAAAA(52-56), and (F) AAAAA(62-66). Bars, $1 \mu \mathrm{m}$. Cells synthesizing FlgE AAAAA(27-31), AAAAA(32-36), or AAAAA(57-61) were aflagellate and are not shown. Histograms display the number of cells ( $y$ axis) with numbers of flagella per cell ( $x$ axis). Means and standard deviations for $N$ cells are shown. Asterisks indicate that flagella numbers were significantly $(P<0.05)$ different compared to cells producing FlgE wild-type, analyzed using a two-tailed Mann-Whitney $U$ test. (JPG 5827 kb)

Additional file 7: Schematic distribution of FlgE molecules in the hook. The distal $\operatorname{rod}(\mathrm{FlgG})$, the hook (FlgE), and the filament (FliC) are helical structures characterized by rotation and rise along their axis, resulting in structures consisting of 11 protofilaments marked here by letters $A$ to $\mathrm{K}$. Each rectangle represents a molecule of FlgE (in the case of the hook). The numbers indicate the sequential order of the molecules as the structure is built. Yellow arrows indicate some of the interactions with close neighbors. (JPG $5849 \mathrm{~kb}$ )

Additional file 8: Strains of bacteria and plasmids. (DOCX $44 \mathrm{~kb}$ ) Additional file 9: Oligonucleotide primers. (DOCX $45 \mathrm{~kb}$ )

\section{Acknowledgements}

We thank all the members of the Trans-membrane Trafficking Unit (OIST) for the discussions about the project. We thank Tohru Minamino (Osaka University, Japan) for providing us with polyclonal antibodies to Salmonella FlgE and FliC proteins. We thank Toshio Sasaki and Toshiaki Mochizuki (OIST) for help with electron microscopy. We are grateful to Eric Martz (University of Massachusetts, Amherst, USA) for critical reading of the manuscript and for preparing the interactive pages on http://proteopedia.org/w/Samatey/5. We thank Olga A. Elisseeva (Okinawa Institute of Science and Technology Graduate University, Japan) for the critical discussions and for reading the manuscript. We are grateful to Keiichi Namba (Osaka University, Japan) for his support. We are grateful to Olesya Gusachenko (University of St Andrews, UK) for producing the schematic illustration of the bacterial flagellum.

\section{Funding}

This work was supported by a direct funding from OIST to FAS.

\section{Availability of data and materials}

All data generated or analyzed during this study are included in this published article and its Additional files.

Interactive 3D views of ID-Rod-Stretch and its interactions are reported here: http://proteopedia.org/w/Samatey/5

\section{Authors' contributions}

FAS and CSB designed the mutations and experiments. CSB and IVM performed the experiments. ASK studied the disordered segment using online prediction software. PLF made the molecular modeling calculations. CSB and FAS wrote the manuscript with input from all the authors. FAS was responsible for the overall project strategy and management. All authors read and approved the final manuscript. 


\section{Competing interests}

The authors declare no competing financial interests.

\section{Publisher's Note}

Springer Nature remains neutral with regard to jurisdictional claims in published maps and institutional affiliations.

\section{Author details}

'Trans-membrane Trafficking Unit, Okinawa Institute of Science and Technology Graduate University, 1919-1 Tancha, Onna, Kunigami, Okinawa 904-0495, Japan. ${ }^{2}$ Voiland School of Chemical Engineering and Bioengineering, Washington State University, Pullman, Washington, USA. ${ }^{3}$ Department of Biological Chemistry, University of Michigan Medical School, Ann Arbor, Michigan, USA.

Received: 26 July 2017 Accepted: 10 October 2017 Published online: 27 October 2017

\section{References}

1. Gething MJ, Sambrook J. Protein folding in the cell. Nature. 1992;355:33-45.

2. Huang PS, Boyken SE, Baker D. The coming of age of de novo protein design. Nature. 2016;537:320-7.

3. Dill KA, MacCallum JL. The protein-folding problem, 50 years on. Science. 2012;338:1042-6

4. Oldfield CJ, Dunker AK. Intrinsically disordered proteins and intrinsically disordered protein regions. Annu Rev Biochem. 2014;83:553-84.

5. Samatey FA, Imada K, Nagashima S, Vonderviszt F, Kumasaka T, Yamamoto M, Namba K. Structure of the bacterial flagellar protofilament and implications for a switch for supercoiling. Nature. 2001;410:331-7.

6. Samatey FA, Matsunami H, Imada K, Nagashima S, Shaikh TR, Thomas DR, Chen JZ, DeRosier DJ, Kitao A, Namba K. Structure of the bacterial flagellar hook and implication for the molecular universal joint mechanism. Nature. 2004;431:1062-8

7. Yonekura K, Maki-Yonekura S, Namba K. Complete atomic model of the bacterial flagellar filament by electron cryomicroscopy. Nature. 2005:424:643-50.

8. Berg HC, Anderson RA. Bacteria swim by rotating their flagellar filaments. Nature. 1973;245:380-2.

9. Macnab RM. How bacteria assemble flagella. Annu Rev Microbiol. 2003; $57: 77-100$

10. Stallmeyer MJ, Aizawa S, Macnab RM, DeRosier DJ. Image reconstruction of the flagellar basal body of Salmonella typhimurium. J Mol Biol. 1989;205:519-28.

11. Cohen EJ, Hughes KT. Rod-to-hook transition for extracellular flagellum assembly is catalyzed by the L-ring-dependent rod scaffold removal. J Bacteriol. 2014;196:2387-95.

12. Jones CJ, Macnab RM, Okino H, Aizawa S. Stoichiometric analysis of the flagellar hook-(basal-body) complex of Salmonella typhimurium. J Mol Biol. 1990;212:377-87.

13. Wagenknecht T, DeRosier DJ, Aizawa S, Macnab RM. Flagellar hook structures of Caulobacter and Salmonella and their relationship to filament structure. J Mol Biol. 1982;162:69-87.

14. Aizawa SI, Dean GE, Jones CJ, Macnab RM, Yamaguchi S. Purification and characterization of the flagellar hook-basal body complex of Salmonella typhimurium. J Bacteriol. 1985;161:836-49.

15. Homma M, Kutsukake K, Hasebe M, lino T, Macnab RM. FlgB, FlgC, FlgF and FlgG, a family of structurally related proteins in the flagellar basal body of Salmonella typhimurium. J Mol Biol. 1990;211:465-77.

16. Fujii T, Kato T, Hiraoka KD, Miyata T, Minamino T, Chevance FF, Hughes KT, Namba K. Identical folds used for distinct mechanical functions of the bacterial flagellar rod and hook. Nat Commun. 2017;8:14276.

17. Fujii T, Kato T, Namba K. Specific arrangement of alpha-helical coiled coils in the core domain of the bacterial flagellar hook for the universal joint function. Structure. 2009;17:1485-93.

18. Yoon Y-H, Barker CS, Bulieris PV, Matsunami H, Samatey FA. Structural insights into bacterial flagellar hooks similarities and specificities. Sci Rep. 2016:6:35552. doi:10.1038/srep35552.

19. Matsunami H, Barker CS, Yoon Y-H, Wolf M, Samatey FA. Complete structure of the bacterial flagellar hook reveals extensive set of stabilizing interactions. Nat Commun. 2016;7:13425. doi:10.1038/ncomms13425.
20. Shaikh TR, Thomas DR, Chen JZ, Samatey FA, Matsunami H, Imada K, Namba K, DeRosier DJ. A partial atomic structure for the flagellar hook of Salmonella typhimurium. Proc Natl Acad Sci U S A. 2005;102:1023-8.

21. Arnold K, Bordoli L, Kopp J, Schwede T. The SWISS-MODEL workspace: a web-based environment for protein structure homology modelling. Bioinformatics. 2006;22:195-201.

22. Biasini M, Bienert S, Waterhouse A, Arnold K, Studer G, Schmidt T, Kiefer F, Gallo Cassarino T, Bertoni M, Bordoli L, Schwede T. SWISS-MODEL: modelling protein tertiary and quaternary structure using evolutionary information. Nucleic Acids Res. 2014;42:W252-8. doi:10.1093/nar/gku340.

23. Chevance FF, Hughes KT. Coordinating assembly of a bacterial macromolecular machine. Nat Rev Microbiol. 2008;6:455-65.

24. Rauscher S, Pomès R. Structural disorder and protein elasticity. Adv Exp Med Biol. 2012;725:159-83.

25. Babu MM, van der Lee R, de Groot NS, Gsponer J. Intrinsically disordered proteins: regulation and disease. Curr Opin Struct Biol. 2011;21:432-40.

26. Berg HC. The rotary motor of bacterial flagella. Annu Rev Biochem. 2003;72:19-54

27. Brown MT, Steel BC, Silvestrin C, Wilkinson DA, Delalez NJ, Lumb CN, Obara B, Armitage JP, Berry RM. Flagellar hook flexibility is essential for bundle formation in swimming Escherichia coli cells. J Bacteriol. 2012;194:3495-501.

28. Furuta T, Samatey FA, Matsunami H, Imada K, Namba K, Kitao A. Gap compression/extension mechanism of bacterial flagellar hook as the molecular universal joint. J Struct Biol. 2007;157:481-90.

29. Beeby M, Ribardo DA, Brennan CA, Ruby EG, Jensen GJ, Hendrixson DR. Diverse high-torque bacterial flagellar motors assemble wider stator rings using a conserved protein scaffold. Proc Natl Acad Sci U S A. 2016:113:E1917-26.

30. Sievers F, Wilm A, Dineen D, Gibson TJ, Karplus K, Li W, Lopez R, McWilliam H, Remmert M, Söding J, Thompson JD, Higgins DG. Fast, scalable generation of high-quality protein multiple sequence alignments using clustal omega. Mol Syst Biol. 2011;7:539. doi:10.1038/msb.2011.75.

31. Romero P, Obradovic Z, Li X, Garner EC, Brown CJ, Dunker AK. Sequence complexity of disordered protein. Proteins. 2001:42:38-48.

32. Wang C, Bradley P, Baker D. Protein-protein docking with backbone flexibility. J Mol Biol. 2007;2:503-19.

33. Kim DE, Chivian D, Baker D. Protein structure prediction and analysis using the Robetta server. Nucleic Acids Res. 2004;32:W526-31.

34. Michaud-Agrawal N, Denning EJ, Woolf TB, Beckstein O. Software news and updates MDAnalysis: a toolkit for the analysis of molecular dynamics simulations. J Comput Chem. 2011;32:2319-27.

35. Humphrey W, Dalke A, Schulten K. VMD: visual molecular dynamics. Mol Graph. 1996;14:33-8.

36. Yamaguchi S, Fujita $H$, Sugata $K$, Taira $T$, lino $T$. Genetic analysis of $H 2$, the structural gene for phase-2 flagellin in Salmonella. J Gen Microbiol. 1984;130:255-65.

37. Ryu J, Hartin RJ. Quick transformation in Salmonella typhimurium LT2. Biotechniques. 1990;8:43-5

38. Ohnishi K, Ohto Y, Aizawa S, Macnab RM, lino T. FlgD is a scaffolding protein needed for flagellar hook assembly in Salmonella typhimurium. Jacteriol. 1994;176:2272-81.

39. Pearson BM, Gaskin DJ, Segers RP, Wells JM, Nuijten PJ, van Vliet AH. The complete genome sequence of Campylobacter jejuni strain 81116 (NCTC11828). J Bacteriol. 2007;189:8402-3.

40. Datsenko KA, Wanner BL. One-step inactivation of chromosomal genes in Escherichia coli K-12 using PCR products. Proc Natl Acad Sci U S A. 2000:97:6640-5.

41. Cherepanov PP, Wackernagel W. Gene disruption in Escherichia coli: Tc ${ }^{R}$ and $\mathrm{Km}^{\mathrm{R}}$ cassettes with the option of Flp-catalyzed excision of the antibiotic-resistance determinant. Gene. 1995;158:9-14.

42. Ohnishi K, Fan F, Schoenhals GJ, Kihara M, Macnab RM. The FliO, FliP, FliQ and FliR proteins of Salmonella typhimurium: putative components for flagellar assembly. J Bacteriol. 1997;179:6092-9.

43. Green MR, Sambrook J. Molecular cloning: a laboratory manual. 4th ed. New York: Cold Spring Harbor Laboratory Press; 2012.

44. Davis L, Young K, DiRita V. Genetic manipulation of Campylobacter jejuni. Curr Protoc Microbiol. 2008;Chapter 8:Unit 8A.2.1-8A.2.17. doi:10.1002/ 9780471729259 mc08a02s10.

45. Karlyshev AV, Wren BW. Development and application of an insertional system for gene delivery and expression in Campylobacter jejuni. Appl Environ Microbiol. 2005;71:4004-13. 
46. Cameron A, Gaynor EC. Hygromycin B and apramycin antibiotic resistance cassettes for use in Campylobacter jejuni. PLoS One. 2014;9:e95084. doi:10.1371/journal.pone.0095084.

47. Toker AS, Kihara M, Macnab RM. Deletion analysis of the FliM flagellar switch protein of Salmonella typhimurium. J Bacteriol. 1996;178:7069-79.

48. Hendrixson DR, DiRita VJ. Transcription of $\sigma^{54}$-dependent but not $\sigma^{28}$ dependent flagellar genes in Campylobacter jejuni is associated with formation of the flagellar secretory apparatus. Mol Microbiol. 2003;50:687-702.

49. Barker CS, Inoue T, Meshcheryakov IV, Kitanobo S, Samatey FA. Function of the conserved FHIPEP domain of the flagellar type III export apparatus, protein FlhA. Mol Microbiol. 2016;100:278-88.

50. Minamino T, Macnab RM. Components of the Salmonella flagellar export apparatus and classification of export substrates. J Bacteriol. 1999;181:1388-94.

51. Konishi M, Kanbe M, McMurry JL, Aizawa S. Flagellar formation in

C-ring-defective mutants by overproduction of Flil, the ATPase specific for flagellar type III secretion. J Bacteriol. 2009;191:6186-91.

Submit your next manuscript to BioMed Central and we will help you at every step:

- We accept pre-submission inquiries

- Our selector tool helps you to find the most relevant journal

- We provide round the clock customer support

- Convenient online submission

- Thorough peer review

- Inclusion in PubMed and all major indexing services

- Maximum visibility for your research

Submit your manuscript at www.biomedcentral.com/submit
Biomed Central 